\title{
ABBREVIATIONS IN NOTES
}

$\begin{array}{ll}\text { BMA } & \text { British Medical Association } \\ B M J & \text { British Medical Journal } \\ \text { CMAC } & \text { Contemporary Medical Archives Centre } \\ \text { CO } & \text { Colonial Office } \\ \text { EAS } & \text { East African Standard } \\ \text { EAMJ } & \text { East African Medical Journal } \\ \text { ES } & \text { Eugenics Society } \\ \text { IMC/CBMS } & \text { International Missionary Council/Conference of British } \\ & \text { Missionary Societies } \\ \text { KEAMJ } & \text { Kenya and East African Medical Journal } \\ \text { KNA } & \text { Kenya National Archives } \\ \text { KSSRI } & \text { Kenya Society for the Study of Race Improvement } \\ \text { NA } & \text { National Archives } \\ \text { RH } & \text { Rhodes House Library, Oxford }\end{array}$

